\title{
HLA Phenotypes and Diabetic Retinopathy
}

\author{
E. Möller ${ }^{1}$, B. Persson ${ }^{2}$, and G. Sterky ${ }^{2}$ \\ ${ }^{1}$ Transplantation Immunology Laboratory, Huddinge Hospital and ${ }^{2}$ Department of Pediatrics, St. Göran's Hospital, Karolinska Institute \\ Medical School, Stockholm, Sweden
}

\begin{abstract}
Summary. The incidence of HLA antigens B8, BW15, DW3 and DW4 was found to be significantly increased in 99 patients with growth onset, insulindependent diabetes of more than 15 years duration. Different degrees of retinopathy were seen in $75 \%$ of the patients. No significant correlation between the presence of specific HLA alleles and the stage of retinopathy was found. We have discussed the possibility that all patients who develop diabetes have identical disease-predisposing genes, irrespective of their HLA alleles. If this was the case, the HLA phenotype would not determine the risk of developing diabetic retinopathy.
\end{abstract}

Key words: Insulin-dependent diabetes, retinopathy, HLA antigens.

There is now ample evidence that a positive association exists between juvenile (insulin-dependent) diabetes and HLA-B8 and BW15 in the Caucasian population $[1,2]$. The potential importance of these findings for the pathogenesis and course of diabetes is at present difficult to assess. A number of hypotheses have been advanced to explain how genetic factors may regulate the occurrence of diabetes [3, $4,5,6]$. On the other hand, the importance of the HLA-phenotypes for long-term prognosis of juvenile diabetes has hardly been investigated.

Our study was undertaken to test the hypothesis that diabetic retinopathy is associated with certain HLA antigens or a combination thereof. Results may contribute to the discussion of genetic versus metabolic determinants of diabetic microangiopathy.

\section{Material and Methods}

All children with diabetes enrolled in Stockholm schools in 1960 form the primary material [7]. In 1976 , when this study was undertaken, there were 99 patients available out of 143 in the primary material. Their present age varied between 22 and 34 years, with a mean of 28 years. Nine were known to have died, 20 were unwilling to participate and 15 could not be traced. Month and age at onset, duration of diabetes and family history of diabetes in first degree relatives were recorded.

In 1975, information on retinopathy was gathered from ophthalmologists in charge of each diabetic patient. Retinopathy was grouped into four stages [8]. Patients $(n=10)$ who had undergone photo-coagulation on one or both eyes, were all considered to belong at least to the stage reached at the time of coagulation, if not otherwise stated by the ophthalmologist.

All patients were HLA-typed using the microcytotoxicity technique described by KissmeyerNielsen and Kjerbye [9] for definition of HLA-A, $-B$ and $-C$ alleles. Furthermore, HLA-D typing was performed with well defined homozygous "typing" cells, using the technique described by Mempel et al. [10] and Jørgensen et al. [11]. The exact details of the method employed in this series of experiments have been carefully described elsewhere [12].

The control series of individuals $(\mathrm{n}=272)$ for HLA-A, $-\mathrm{B}$ and $-\mathrm{C}$ determinants were blood donors consecutively typed in our laboratory during the last two years using identical reagents. The control series for determination of frequencies of HLA-DW3 and HLA-DW4 comprised partly of blood donors published in an earlier report $[12,13]$ as well as 40 laboratory personnel recently typed in our labora- 
tory with identical "typing" cells as used in the present series.

Statistical evaluation of results was performed using the $\chi^{2}$-test and Yates' correction for small numbers.

\section{Results}

The antigens HLA-B8 and HLA-BW15 occurred significantly more often in patients with juvenile diabetes than in controls $(p<0.001)$; the frequency for HLA-B8 was $48.5 \%$ versus $24.6 \%$ and for HLA-BW15 $42.5 \%$ versus $20.6 \%$ in patients and controls respectively. The frequency of HLA-B7 was significantly $(\mathrm{p}<0.001)$ decreased $(11 \%$ in patients and $28 \%$ in controls) but that of HLA-B12 similar ( $p>0.05), 15 \%$ and $22 \%$ respectively.

There was no evidence of seasonal variation at onset and the distribution of HLA-types was uniform. The peak age of onset was 6-7 years. There was no evidence of an association between certain HLA-phenotypes and age at onset. A family history of diabetes was reported in 18 per cent of the patients $(n=83)$. A positive family history showed no association with HLA-B8 or HLA-BW15.

Studies on the frequency of the HLA-B8 associated determinant HLA-DW3 and of the BW15 associated antigen DW4 revealed a slightly increased occurrence of DW3 in diabetic patients,

Table 1. Frequencies of HLA-DW3 and DW4 in juvenile diabetics and normal individuals. Swedish and Danish ${ }^{\mathrm{a}}$ material

\begin{tabular}{lll} 
Non-diabetics & Diabetics \\
\hline Swedish Danish & Swedish Danish
\end{tabular}

HLA-DW3 (34/176)19\% (9/55)16\% (22/74)30\% (29/50)58\% HLA-DW4 (25/133)19\% (9/55)16\% (41/79)52\% (33/75)42\%

a Nerup et al. [4] compared to controls $\left(0.05>p<0.01, \chi^{2}-3.9\right)$ and a statistically significant increase of DW4 (p $\left.<0.001, \chi^{2}-26.9\right)$ in diabetics compared to controls (Table 1).

Retinopathy was diagnosed in $74 \%$ of the total material. The distribution of patients in the various stages were: microaneurysms only $30,+$ haemorrhages $17,+$ exudates 14 , and proliferative lesions 12. The frequency of retinopathy was similar in patients with or without HLA-B8, HLA-BW15 (Table 2) and HLA-B7 respectively. There was no difference in the occurrence of retinopathy in patients with or without DW3 and/or DW4 respectively.

In the group of diabetics $(n=46)$ of $\geq 21$ years of duration, the presence or absence of retinopathy was unrelated to HLA-B8 or HLA-BW15 (Table 2). A further analysis was undertaken with respect to the various stages of retinopathy. There was a non-significant higher incidence of advanced retinopathy (i.e. more than haemorrhages) in patients with HLA-BW15. This increase was even more marked, but still statistically not significant, for patients positive for both B8 and BW15. Finally, proliferative retinopathy occurred in $39 \%$ (7/18) of patients with BW15 and in $25 \%(7 / 28)$ of BW15 negative patients $\left(\mathrm{p}>0.05, \chi^{2}-0.45\right)$.

\section{Discussion}

We have in this series confirmed the increased incidence of HLA-B8 and DW3 as well as BW15 and DW4 in patients with insulin-dependent diabetes [14]. Thus, genetic factors within the HLA region regulate the occurrence of diabetes. Nothing is as yet known about the genetic basis for this association, but it has been suggested that the disease might, at least in part, be caused by the presence within this region of genes which regulate the immune response (IR or IS genes). Since many differ-

Table 2. The frequency of diabetic retinopathy in relation to HLA-B8 and BW15 in patients with at least 15 years duration of diabetes

\begin{tabular}{|c|c|c|c|c|c|c|}
\hline & \multicolumn{6}{|c|}{ Retinopathy } \\
\hline & \multicolumn{3}{|c|}{$\begin{array}{l}\text { Duration of diabetes } \\
\geq 15 \text { years }(n=99)\end{array}$} & \multicolumn{3}{|c|}{$\begin{array}{l}\text { Duration of diabetes } \\
\geqslant 21 \text { years }(n=46)\end{array}$} \\
\hline & $\mathbf{n}$ & $\begin{array}{l}\text { Retinopathy } \\
\text { present }\end{array}$ & $\begin{array}{l}\text { Per cent } \\
\text { with retinopathy }\end{array}$ & $\mathrm{n}$ & $\begin{array}{l}\text { Retinopathy } \\
\text { present }\end{array}$ & $\begin{array}{l}\text { Per cent } \\
\text { with retinopathy }\end{array}$ \\
\hline HLA-B8 pos & 48 & 38 & 79.2 & 22 & 18 & 81.8 \\
\hline HLA-B8 neg & 51 & 35 & 68.6 & 24 & 20 & 83.8 \\
\hline HLA-BW15 pos & 42 & 29 & 69.1 & 18 & 15 & 83.3 \\
\hline HLA-BW15 neg & 57 & 44 & 77.2 & 28 & 23 & 82.1 \\
\hline HLA-B8 and BW15 pos & 15 & 11 & 73.3 & 6 & 4 & 66.7 \\
\hline HLA-B8 and BW15 neg & 24 & 17 & 70.8 & 12 & 9 & 75.0 \\
\hline
\end{tabular}


ent diseases have been shown to be associated with specific HLA alleles (for ref., see [15]), diseasepredisposing genes are located in linkage disequilibrium with specific products of distinct HLA loci. The alleles B8 and BW15 have been shown to occur in linkage disequilibrium with the HLA-D alleles W3 and W4 respectively.

When discussing the HLA linked factors, which are important for the development of insulin-dependent diabetes, it is important to point out that not all individuals carrying either the B8-DW3 haplotype or the BW15-DW4 haplotype are also carriers of genes predisposing for development of diabetes. However, if these haplotypes occur in a first degree relative with the disease, the likelihood that these haplotypes also contain disease-predisposing genes is considerable. Consequently, it is impossible to tell whether a person who lacks both the B8-DW3 and the BW15-DW4 haplotype carries disease-predisposing genes in the HLA region or not. It is however, conceivable that all patients with juvenile insulin-dependent diabetes have identical HLA linked disease-predisposing genes, whether they have B8-DW3 and BW15-DW4 or not.

It follows, from the studies on the association between disease and HLA genes, that only diseasepredisposing genes which are present on HLA haplotypes shown to contain alleles in linkage disequilibrium, could be associated with a particular HLA allele in a random patient population. Therefore, it would also be impossible to tell if there is any genetic difference between two individuals with diabetes only from determinations of HLA alleles.

Classification of retinopathy using consecutive stages is difficult due to the great individual variations displayed by the disease, and the often fortuitous occurrence of the lesions $[8,16]$. During the first 20 years of diabetes, the incidence of retinopathy increases with time. After 20 years, few further cases seem to be added [8]. Furthermore, many patients' retinopathy may never proceed from the stage of microaneurysms. In the analysis we have tried to pay attention to these factors.

There was no striking relationship between any of the HLA phenotypes and retinopathy. However, a tendency was seen for more advanced stages of retinopathy in patients with $\mathrm{BW} 15$. This observation is in accordance with that of Nerup [17] on Danish material but contrary to that of Barbosa et al. [18] who investigated insulin-dependent diabetics with retinopathy awaiting kidney transplant and found a significantly higher frequency only of A1 and B8.

The development and pattern of retinopathy has been reported to be more similar in concordant rather than in discordant pairs of diabetic twins [19].
These findings, as well as the observations of Nerup [17] and Barbosa et al. [18], suggest a genetic contribution to the aetiology of diabetic retinopathy. However, there is good reason to believe that most, if not all, patients that develop the disease have identical disease-predisposing genes, irrespective of their HLA alleles. Therefore, our results showing no significant correlation between specific HLA alleles and the course of diabetes in terms of retinopathy are not unexpected.

However, we cannot rule out the possibility of a genetic influence on the achievable level of metabolic regulation at onset of diabetes and during subsequent years. The relative importance of various aetiological factors explaining the course of diabetic retinopathy remains largely unknown.

Acknowledgements. The skilful technical assistance of Miss B. Hagström, Mrs U. Klingwall, and Mrs L. Markling is gratefully acknowledged. The present investigation was supported by grants from the Swedish Medical Research Council (project No 04799) and the Swedish Diabetic Association.

\section{References}

1. Singal, D.P., Blajchman, M. A.: Histocompatibility (HL-A) antigens, lymphocytotoxic antibodies and tissue antibodies in patients with diabetes mellitus. Diabetes 22, 429-432 (1972)

2. Nerup, J., Platz, P., Ortved Andersen, O., Christy, M., Lyngsøe, J., Poulsen, J. E., Ryder, L. P., Staub Nielsen, L., Thomsen, M., Svejgaard, A.: HL-A antigens and diabetes mellitus. Lancet 1974 II, 864-866

3. Cudworth, A. G., Woodrow, J.C.: Evidence for HLA-linked genes in 'juvenile' diabetes mellitus. Br. Med. J. 1975 III, $133-135$

4. Nerup, J., Ortved Andersen, O., Christy, M., Platz, P., Ryder, P., Thomsen, M., Svejgaard, A.: HLA, auto-immunity, virus and the pathogenesis of juvenile diabetes mellitus. In: $O$. Ortved Andersen, T. Deckert, J. Nerup (Eds.): Immunological Aspects of Diabetes Mellitus. Acta Endrocrinol. (Kbh.) 83, (Suppl. 205) 167-175 (1976)

5. Cudworth, A. G., Gamble, D. R., White, G. B.B., Lendrum, R., Woodrow, J.C., Bloom, A.: Aetiology of juvenile onset diabetes. A prospective study. Lancet 1977 I, 385-388

6. Irvine, W. J.: Classification of idiopathic diabetes. Lancet 1977 I, 638-642

7. Sterky, G.: Diabetic school children. Acta Paediatr. Scand. [Suppl. 144] 52 (1963)

8. Larsson, Y., Sterky, G.: Long-term prognosis in juvenile diabetes. Acta Paediatr. Scand. [Suppl. 130] 51 (1962)

9. Kissmeyer-Nielsen, F., Kjerbye, K.E.: Lymphocytotoxic micro-technique. Purification of lymphocytes by flotation. In: E. S. Curtoni, P. L. Mattiuz, R. M. Tosi (Eds.): Histocompatibility Testing, p. 381. Copenhagen: Munksgaard Publishing House 1967

10. Mempel, W., Grosse-Wilde, H., Baumann, P., Netzel, B., Steinbauer-Rosenthal, I., Scholz, S., Bertrams, J., Albert, E.D.: Population genetics of the MLC response. Typing for MLC determinants using homozygous and heterozygous reference cells. Transplant. Proc. 5, 1529-1534 (1973)

11. Jørgensen, F. H., Lamm, L. U., Kissmeyer-Nielsen, F.: Mixed lymphocyte cultures with inbred individuals. An approach to MLC typing. Tissue Antigens 3, 323-339 (1973) 
12. Thorsby, E., Helgesen, A., Rankin, B., Möller, E., Kaakinen, A.: Identification of five lymphocyte activating determinants in man. Tissue Antigens 6, 147-160 (1975 a)

13. Thorsby, E., Bratlie, A., Helgesen, A., Rankin, B., Solheim, B., Kaakinen, A., Möller, E.: Human MLC activating determinants. In: F. Kissmeyer-Nielsen (Ed.): Histocompatibility Testing, pp. 502-508. Copenhagen: Munksgaard Publishing House 1975 b

14. Thomsen, M., Platz, P., Ortved Andersen, O., Christy, M., Lyngsøe, J., Nerup, J., Rasmussen, K., Ryder, L., Staub Nielsen, L., Svejgaard, A.: MLC typing in juvenile diabetes mellitus and idiopathic Addison's disease. Transplant. Rev. 22, 125-147 (1975)

15. Möller, G. (ed.): HL-A and disease. Transplant. Rev. 22, (1975)

16. Kohner, E.M., Oakley, N.W.: Diabetic retinopathy. Metabolism 24, 1085-1102 (1975)
17. Nerup, J.: In: O. Ortved Andersen, T. Deckert, J. Nerup (Eds.): Immunological Aspects of Diabetes Mellitus. Acta Endocrinol. (Kbh.) [Suppl. 205] 83, 181 (1976)

18. Barbosa, J., Noreen, H., Emme, L., Goetz, F., Simmons, R., De Leiva, A., Najarian, J., Yunis, E.: Histocompatibility (HLA) antigens and diabetic microangiopathy. Tissue Antigens 7, 233-238 (1976)

19. Pyke, D. A., Tattersall, R. B.: Diabetic retinopathy in identical twins. Diabetes 21, 321-322 (1973)

Received: June 10, 1977,

and in revised form: October 4, 1977

Dr. Göran Sterky

St. Göran's Childrens' Hospital

S-112 81 Stockholm

Sweden 